Article

\title{
An Adaptive Approach to Derive Sea Ice Draft from Upward-Looking Acoustic Doppler Current Profilers (ADCPs), Validated by Upward-Looking Sonar (ULS) Data
}

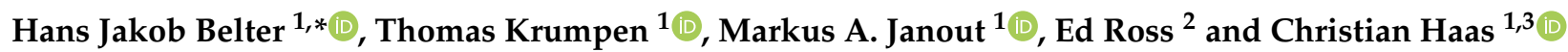 \\ 1 Alfred Wegener Institute, Helmholtz Centre for Polar and Marine Research, Am Handelshafen 12, \\ 27570 Bremerhaven, Germany; tkrumpen@awi.de (T.K.); mjanout@awi.de (M.A.J.); chaas@awi.de (C.H.) \\ 2 ASL Environmental Sciences Inc., Saanichton, BC V8M 1Z5, Canada; ed.ross@trailmarksys.com \\ 3 Institute of Environmental Physics, University of Bremen, Otto-Hahn-Allee 1, 28359 Bremen, Germany \\ * Correspondence: jbelter@awi.de
}

check for

updates

Citation: Belter, H.J.; Krumpen, T.; Janout, M.A.; Ross, E.; Haas, C. An Adaptive Approach to Derive Sea Ice Draft from Upward-Looking Acoustic Doppler Current Profilers (ADCPs), Validated by Upward-Looking Sonar (ULS) Data. Remote Sens. 2021, 13, 4335. https://doi.org/10.3390/ rs13214335

Academic Editor: Andrzej Stateczny

Received: 15 September 2021

Accepted: 26 October 2021

Published: 28 October 2021

Publisher's Note: MDPI stays neutral with regard to jurisdictional claims in published maps and institutional affiliations.

Copyright: (c) 2021 by the authors. Licensee MDPI, Basel, Switzerland. This article is an open access article distributed under the terms and conditions of the Creative Commons Attribution (CC BY) license (https:/ / creativecommons.org/licenses/by/ $4.0 /)$.

\begin{abstract}
Moored upward-looking Acoustic Doppler Current Profilers (ADCPs) can be used to observe sea ice draft. While previous studies relied on the availability of auxiliary pressure sensors to measure the instrument depth of the ADCP, we present an adaptive approach that infers instrument depth from ADCP bottom track (BT) mode measurements of error velocity and range. The ADCPderived ice draft time series are validated with data from adjacent Upward-Looking Sonar (ULS) moorings. We demonstrate that this method can be used to obtain daily mean sea ice draft time series that, on average, are within $20 \%$ of ULS-derived draft time series. ULS and ADCP ice draft time series were observed by four moorings in the Laptev Sea and show correlations between 0.7 and 0.9. This new approach is not a substitute for high-frequency, high-precision ULS measurements of ice draft but it provides a low-cost opportunity to derive daily mean ice draft time series accessing existing ADCP data that have not been not used for that purpose to date. This method has the potential to close data gaps and extend existing ice draft time series in all ice-covered regions and supports the validation of sea ice thickness products from satellite missions such as CryoSat-2, SMOS or ENVISAT.
\end{abstract}

Keywords: sea ice thickness; sonar; Laptev Sea

\section{Introduction}

Moored Upward-Looking Sonars (ULS) are the primary source for high-resolution and long-duration time series of sea ice draft [1]. They sample at high frequencies (up to $0.5 \mathrm{~Hz}$ ) using a single narrow vertical beam and have been used for quite some time in several ice-covered regions around the world [2-9]. In regions where ULS data are not available or funding constraints prohibited the deployment of ULSs, upward-looking Acoustic Doppler Current Profiler (ADCP) records have been utilised to derive sea ice draft information [10-13].

In the world oceans, ADCPs are primarily used to measure current velocity profiles. When operated in bottom track (BT) mode, such setups allow for measurements of ice drift velocities that are commonly used to complement ULS measurements of sea ice draft $[1,9,14,15]$. As suggested by Visbeck and Fischer [16] a combination of ADCPs and precise pressure sensors to determine the instrument depth also allows for the derivation of sea ice draft. However, compared to standard ULS systems, the inherent instrument setup of upward-looking ADCPs, with a larger beamwidth and default beam angles to the vertical, leads to larger uncertainties in the derived sea ice draft values. This is the case even if the instrument depth is precisely known from pressure measurements and correction terms are applied to overcome the ADCP's deficiencies $[10,12,16]$. Consequently, ice draft derivations based on ADCP BT data are less common and simply a way of overcoming ULS data gaps. 


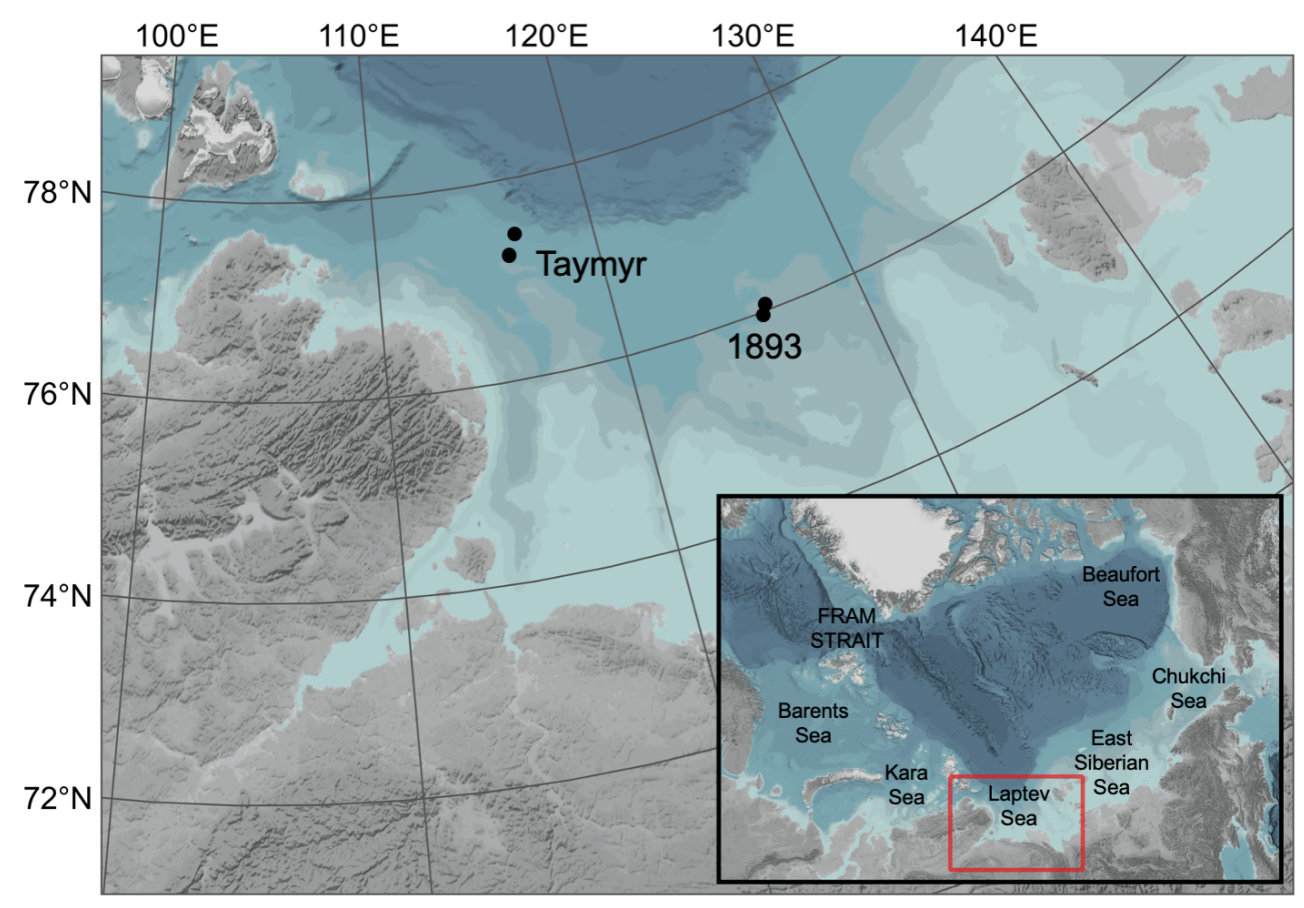

Figure 1. Map of the Laptev Sea showing the 2013-2015 locations of Upward-Looking Sonar (ULS) and Acoustic Doppler Current Profiler (ADCP) mooring sites. Arctic Ocean bathymetry in the background is based on the RTopo-2 product [17].

One region that is lacking long-term ULS ice draft measurements is the Laptev Sea in the Eastern Arctic Ocean (Figure 1). The Laptev Sea is considered to be a key source region of Arctic sea ice [5,18-20]. From October through June, the Laptev Sea is mainly covered by first-year ice $[21,22]$. Sea ice is formed in polynyas on the shallow shelves (water depths between 15 and $200 \mathrm{~m}$ ) and continuously transported north towards the central Arctic Ocean by the prevailing offshore-directed winds [19,23]. Despite the importance of the region for the formation of Arctic sea ice, long-term in situ measurements of sea ice draft are not available. ULS measurements for scientific purposes were only carried out for two years (2013-2015) within the framework of the Russian-German research cooperation 'Laptev Sea Systems'. As the access to this region is very limited and further ULS moorings have not been deployed over the past few years, high-resolution longduration ice draft measurements are sparse. Oceanographic moorings with upwardlooking ADCPs on the other hand, were operated in the Laptev Sea over much longer time periods (2003-2016) [24]. However, unlike in previous studies [10-13], the available ADCP data were not complemented by reliable auxiliary pressure data to determine instrument depth. Therefore, the extension of the available ULS-based sea ice draft time series was not possible in the Laptev Sea.

In order to overcome the lack of ice draft data in this important source region of Arctic sea ice, we present an adaptive approach to derive ice draft time series from ADCP data that are not based on additional pressure data to determine instrument depth. This new approach builds on previous techniques to derive ice draft from ADCPs but its validation relies on the availability of coincidental ULS moorings. The ULS measurements provide reliable reference data for the ice draft derivation from ADCPs, which was not available in previous studies [10]. Similar to Hyatt et al. [12], we provide the means to utilise more available ADCP data records to extend ice draft time series in regions where no other data are available, rather than a substitute for combined ULS and ADCP measurements of ice draft.

Access to the available long-term ADCP data in the Laptev Sea allows an extension of existing ULS-based ice draft time series. This extended time series will support upcoming 
efforts to investigate seasonal and interannual sea ice thickness variability in this vital source region of Arctic sea ice that were not possible until now. Furthermore, these datasets provide unique in situ validation data for sea ice thickness products based on satellite missions such as CryoSat-2, SMOS or ENVISAT.

\section{Materials and Methods}

Two ULSs of the type Ice Profiling Sonar $5(420 \mathrm{kHz}$, manufactured by ASL Environmental Sciences, Victoria, BC, Canada) were deployed in the Laptev Sea in September 2013. In addition, two moorings with upward-looking Teledyne RDI Workhorse $300 \mathrm{kHz}$ Sentinel ADCPs were deployed in the vicinity of the ULS moorings (for distances, see Table 1) over the same time period (Figure 1). All four devices were recovered in September 2014. Both ULS and one ADCP were redeployed until September 2015. The other ADCP was exchanged and the entire mooring newly deployed until September 2015.

Table 1. Distances between ADCP and ULS mooring at the stations 1893 and Taymyr for the two sampling periods (2013-2014 and 2014-2015).

\begin{tabular}{ccc}
\hline Station & $\mathbf{2 0 1 3 / 2 0 1 4}$ & $\mathbf{2 0 1 4 / 2 0 1 5}$ \\
\hline 1893 & $0.33 \mathrm{~km}$ & $0.99 \mathrm{~km}$ \\
Taymyr & $0.35 \mathrm{~km}$ & $2.85 \mathrm{~km}$ \\
\hline
\end{tabular}

Initially, the ADCPs were deployed to provide complementary ice drift velocity data to the obtained ULS draft data. The combination of ULS draft and ADCP ice drift data allows for the conversion of sea ice draft time series into quasi-spatial series. Spatial series of ice draft are used for detailed characterizations of keel shapes and other ice features [1] as well as the estimation of ice volume fluxes. Despite their differing purposes, both systems, ULS and ADCP, are built to determine distances between transducer and reflecting surfaces or scattering particles from the two-way travel time of their emitted and reflected acoustic signal, which allows for the computation of ice draft. However, the specific configuration of the ULS, with one narrow vertical beam and a very brief sound pulse, makes it the primary mooring-deployed device for this task. The high-precision ULS measurements provide an excellent reference for the validation of our approach to derive sea ice draft from ADCP data. For this study, we analysed a total of four ULS/ADCP datasets from two different locations and time periods (Figure 1).

\subsection{Data Processing}

\subsubsection{Upward-Looking Sonar}

The Laptev Sea ULSs were deployed at water depths between 43 and $78 \mathrm{~m}$ (instrument depths between 14 and $23 \mathrm{~m}$ ) and operated with a single vertical beam (beamwidth $1.8^{\circ}$ ) at a sampling frequency of $1 \mathrm{~Hz}$ for range (distance from device to ice-water interface) and $1 / 60 \mathrm{~Hz}$ for auxiliary data (instrument tilt, pressure, and temperature at instrument depth). Sea ice draft $(d)$ was calculated as the difference between instrument depth $(\eta)$ and distance to the ice-water interface:

$$
d=\eta-\beta \cdot r \cdot \cos \theta
$$

where $\beta$ is a calibration factor [25] for the corrected speed of sound in seawater relative to the initially assumed value used when decoding the raw range data, $r$ is the ULS-measured range and $\theta$ is the total instrument tilt from the vertical [25]. The continuous instrument depth time series was computed as follows:

$$
\eta=\left(\frac{p_{u l s}-p_{a t m}}{\rho g}\right)-\Delta D
$$

where $p_{u l s}$ is the ocean pressure at instrument depth, as measured by the ULS. Surface pressure, $p_{a t m}$, was taken from the ECMWF ERA-Interim ( $6 \mathrm{~h}$ sea level pressure) reanalysis 
product [26], $\rho$ is the seawater density, $g$ is the local gravitational acceleration and $\Delta D$ is the vertical spacing between ULS pressure and range sensor [25]. The 2013-2014 (13/14) datasets were processed by ASL Environmental Sciences Inc., while the 2014-2015 (14/15) datasets were processed by the authors using the ASL Ice Profiling Sonar Processing Toolbox [25].

The resulting datasets provide high-frequency ice draft time series for the two locations in the Laptev Sea (Figure 1). According to Ross et al. [1] the theoretical error of ULS-derived ice drafts is within $0.05 \mathrm{~m}$. This error estimate is based on the accuracy and precision of the range measurements, pressure, tilt, and temperature sensors. However, errors may accumulate during the individual processing steps due to the errors inherent in air pressure data, sound-speed estimates, instrument tilt, false targets (like bubbles and biota), signal spikes, beamwidth and footprint effects, and wave penetration into the ice [5]. A detailed description of the individual processing steps and possible uncertainties can be found in the Ice Profiling Sonar Processing Toolbox User's Guide [25] and in Hansen et al. [5].

\subsubsection{Acoustic Doppler Current Profiler}

The moored ADCPs were sampled in bottom track (BT) mode at a frequency of $1 / 60 \mathrm{~Hz}$. However, the raw data output provides hourly values that were calculated as an ensemble average over 60 values. Measurements in BT mode are characterized by longer transmit pulses compared to the water-tracking mode that is used to profile the water column [27]. Additionally, the signal echoes are processed differently (for a detailed explanation, see RDI [27]). The ADCPs measured with four different beams, each with a $3.8^{\circ}$ beamwidth. By default, the beams were mounted at an angle of $20^{\circ}$ to the vertical (Figure 2). BT range to the boundary above was measured by each of the four beams and the final values were corrected for the $20^{\circ}$ mounting angle internally by the ADCP. Prior to further processing, we also corrected for instrument tilts (roll and pitch) that resulted from mooring movement and were not accounted for by the ADCP internally. However, it has to be noted that moorings are constantly moving in the water column and given the temporal resolution of the available datasets, correcting ensemble-averaged BT range values with ensemble-averaged instrument tilts can only be considered a basic approach to correct for mooring movement.

The uncertainty of the measured range is correlated to the instrument depth and amounts to about $\pm 1 \%$ of the total measured range for the current setup. For the depth ranges of the ADCPs used for this study, the BT mode range uncertainty is between \pm 0.3 and $\pm 0.5 \mathrm{~m}$ [27].

The derivation of ice draft records from ADCP data is based on the same processing steps used to compute the draft from ULSs (Equation (1)). However, since the ADCPs primary purpose was to measure velocity fields, it was not configured to measure ice draft with the same accuracy as the ULS. Previous studies $[10,12,13]$ on ice draft derivation from ADCP data applied a number of correction terms in order to obtain ice draft time series. All these studies relied on pressure sensors that were deployed with or integrated into the ADCPs. The additional pressure sensor proved vital for an accurate determination of instrument depth. Older ADCPs, such as the ones deployed in the Laptev Sea between 2013 and 2015, are not necessarily equipped with these additional sensors. The presented approach to derive ice draft from upward-looking ADCPs adapts to the lack of auxiliary pressure data and determines instrument depth using only the BT mode data output provided by the ADCP. 


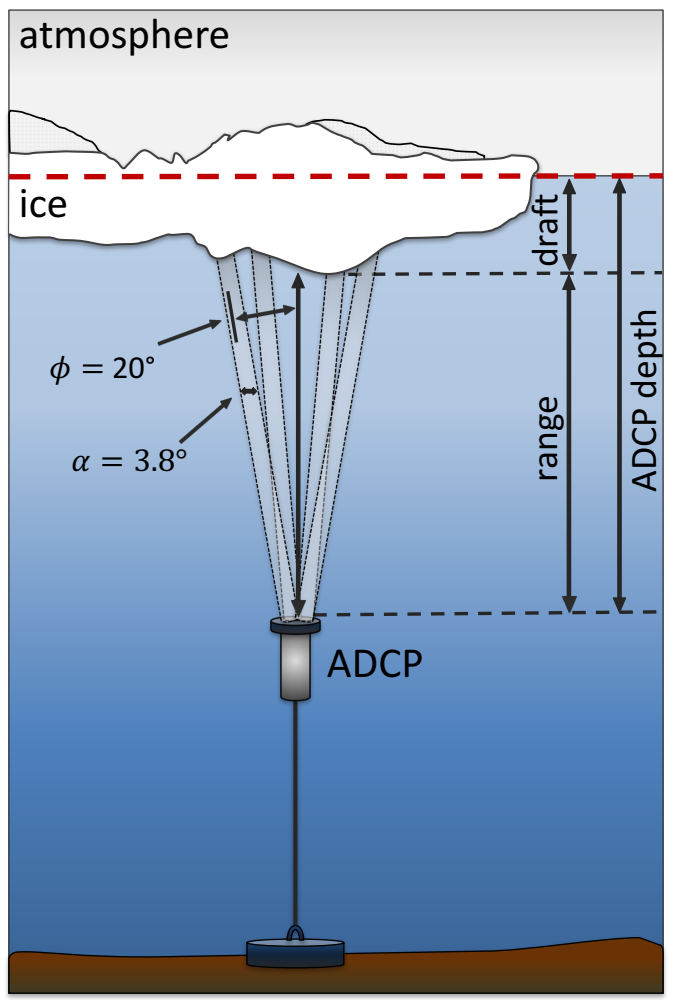

Figure 2. Simple schematic of a moored upward-looking Acoustic Doppler Current Profiler.

We deduce instrument depth from BT mode measurements of surface and error velocity. BT error velocity quantifies the difference in vertical velocity as measured by any two opposite ADCP beams [14], meaning that it provides a measure of the consistency of the velocity measurements at the reflecting surface from the four beams. Belliveau et al. [14] found that error velocities also provide an indication of either ice-covered or open-water conditions. Error velocities and horizontal surface velocities were steady and close to zero during permanent ice cover and became rather noisy when open-water prevailed [13,14]. Hyatt et al. [12] used windowed variances in vertical and error velocities to distinguish between open-water and ice-covered conditions. Since the open-water surface is rather variable and strongly influenced by winds, it is valid to assume that four beams measuring four different areas (Figure 2) are likely to detect inhomogeneities in the velocity field. The ADCPs used here were deployed at depths between 34 and $46 \mathrm{~m}$ which resulted in a minimum (maximum) distance between measurements of two opposing beams of approximately $25 \mathrm{~m}(33.5 \mathrm{~m})$ at the surface. These distances between measurements from the four beams only arose due to the default $20^{\circ}$ angle between the individual beams from the vertical. With higher velocities and noisy signals during open-water periods, the error velocity is bound to increase, indicating inhomogeneous surface velocities. The ADCPs were configured to save flag values in the error velocity output file in cases where error velocities exceeded a threshold value of $1 \mathrm{~m} / \mathrm{s}$.

Following these assumptions, we consider error velocity flag values to be a definitive measure for open-water conditions. Unlike Hyatt et al. [12] we require this information for the detection of ADCP instrument depth rather than to determine sea ice concentration.

Based on the detection of open-water from the error velocity flag values, we consider all BT range values during open-water periods to provide the distance between the ADCP and the water surface- the instrument depth. Figure 3 shows an example of all open-water range values from a single beam of the ADCP deployment at the Taymyr station in 13/14. The ADCP depth is usually strongly affected by currents, which can lead to mooring and instrument knock-down. Figure 3, as well as the roll and pitch time series recorded 
by the ADCPs, confirm mooring movement and the variability of the instrument depth throughout the sampling period.

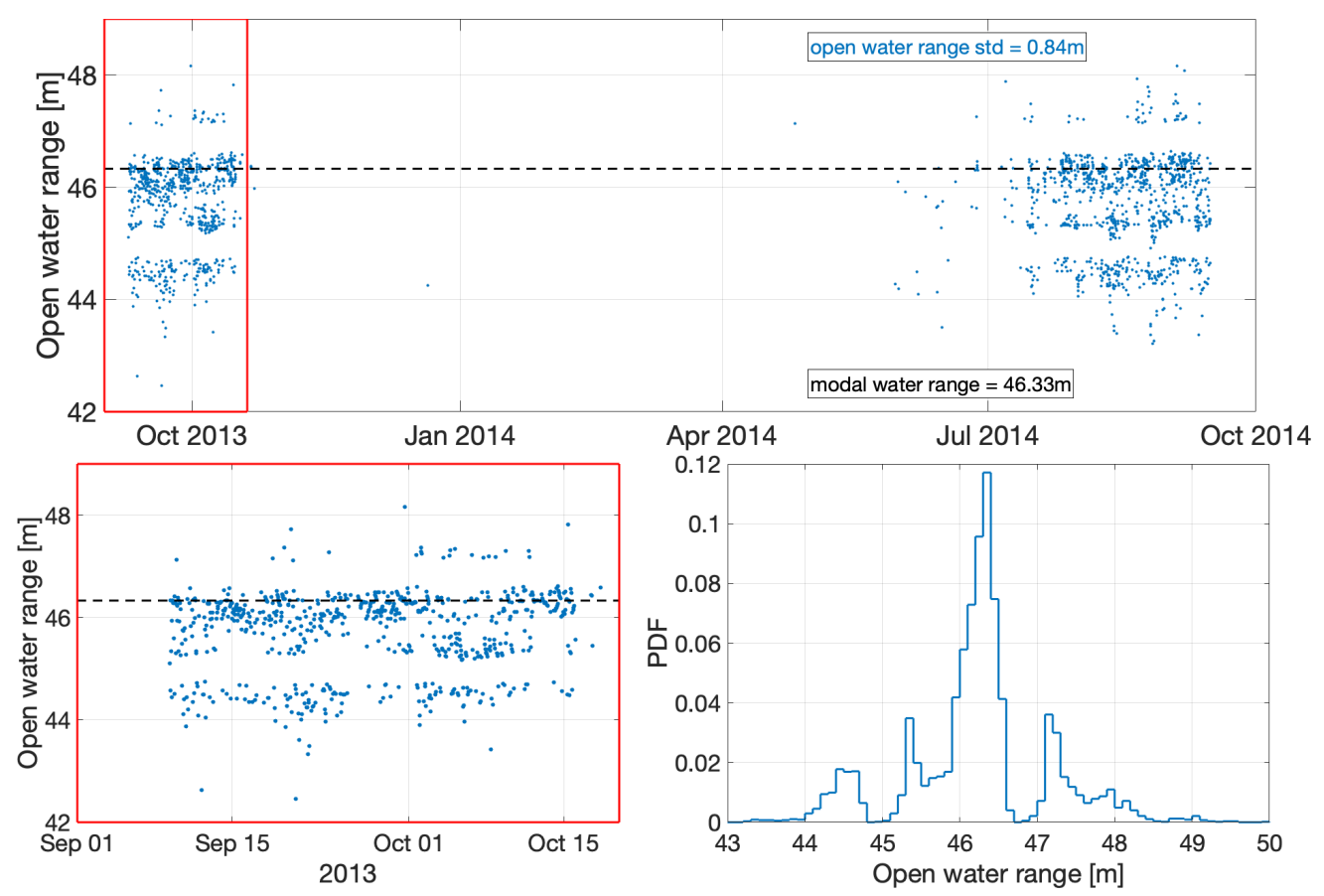

Figure 3. Open-water range values from beam 2 of the Taymyr-13/14 ADCP are shown in blue (top panel). The left panel at the bottom shows the image section of the top panel for the period from 1 September until 20 October 2013. The black dashed line indicates the beam 2 instrument quasi-depth determined from the most frequent open-water range value (derived from distribution with $0.01 \mathrm{~m}$ bins). This depth was considered the constant depth throughout the sampling period and used to calculate the beam 2 sea ice draft time series. Bottom right panel shows the probability density function (PDF) of open-water range values for the Taymyr-13/14 dataset.

During winter, the central Laptev Sea is characterised by a closed ice cover. Accordingly, leads and open-water areas that are detected using the error velocity almost exclusively occur during freeze-up, melt, and ice-free periods (Figure 3). Moreover, periods of open-water that occurred during winter are difficult to detect due to the ADCP's comparably long sampling interval of $1 \mathrm{~min}$ and the internal averaging to hourly values. Narrow openings in the ice were simply not resolved or averaged out. Without any openwater records during the ice-covered period, the determination of a continuous instrument depth time series, such as the high-frequency ULS measurements, is not possible with the available ADCP data. We, therefore, determined a constant instrument depth for the entire sampling period for each ADCP time series. In order to account for offsets between the four ADCP beams, we determined a constant 'quasi-depth' for each beam individually by finding the most frequent (modal) BT range value during open-water periods (Figure 3).

With limited knowledge about water column properties and the long sampling interval, we relied on sound-speed estimates based on the ADCPs temperature measurements and the assumption of constant salinity (measured at mooring deployment) between the $\mathrm{ADCP}$ and the water surface throughout the sampling period [27]. Following these assumptions and limitations for the derivation of ice draft and instrument depth from an $\mathrm{ADCP}$ with no internal pressure sensor Equation (1) is reduced to:

$$
d_{i}=z_{i}-r_{i} \cdot \cos \phi,
$$

where $i$ is the number of beams (four in this case), $z$ is the quasi-depth based on the most frequently occurring BT range value during open-water periods, $r$ is the BT range and $\phi$ is the tilt of the ADCP, which consists of the default beam angle $\left(20^{\circ}\right.$, corrected 
internally) and roll and pitch angles that, given the ADCP configuration, affect the four beams differently [28]. Equation (3) is applied to each beam individually resulting in four separate sea ice draft time series per ADCP.

Since we account for possible offsets between the four beams, in theory, the four draft time series ought to be very similar. However, as mentioned before the default mounting angle between the individual beams led to the measurement of four different areas of ice. After accounting for possible offsets between the beams, the final step before averaging over the four beams is to determine whether individual beams or their data output are erroneous. In this context, we considered physical mechanisms (e.g., tilting of a beam that is not accounted for) that act on individual beams that otherwise performed as expected. To identify erroneous data from individual beams, we calculated the percentage of negative ice draft values throughout the entire sampling period from each beam. In reality, negative draft values are non-existent but, due to our instrument depth assumptions and the limitations of this method, they can occur, especially during freeze-up, melt, and ice-free periods. Hence, depending on the length of the transition time between ice-free and ice-covered periods, the percentage of negative draft values changes. We averaged the percentages over the four beams and calculated their standard deviation. Too high a percentage of negative draft values of one beam compared to the other three is an indication of erroneous data from that beam. We, therefore, excluded data from beams with a percentage of negative draft values outside of one standard deviation of all other beams. The exclusion of data from one or more beams occurred only once for the four ULS/ADCP dataset pairs. Averaging over all remaining beams yields one ice draft time series for each ADCP, with a sampling interval of $1 \mathrm{~h}$.

Values recorded during open-water periods and remaining negative draft values were excluded and daily mean ice drafts were calculated. Averaging the ADCP draft time series to daily mean values is necessary due to the noisiness of the data and the uncertainty that is introduced to the hourly draft values by our estimate of constant instrument depth. ADCP daily mean draft values were calculated for all days with a minimum of $50 \%$ of 'good' data. This threshold prevents daily mean values being distorted by outliers during days with long or frequent open-water periods. ULS reference time series were averaged to daily mean values.

\section{Results}

In contrast with previous studies on ice draft derivation from upward-looking $\mathrm{ADCPs}$ [10], we are able to compare ADCP-derived daily mean ice draft to reference time series based on ULS data. However, it has to be noted that ULS and ADCP were deployed using two different moorings some distance apart. In theory, the two moorings should have been as close to each other as possible in order to depict drift and draft of the same area of ice, but not too close, to avoid acoustic cross-talk between the instruments [2]. Practically, expedition logistics and weather conditions determined the distance between the respective mooring locations. For the comparison of draft time series from the two instruments, the distance between the mooring sites led to the sampling of different pieces of ice. Although we were not measuring the exact same ice at the respective ADCP and ULS moorings, the general ice conditions and the continuous northward transport of ice [19] in those areas of the Laptev Sea are comparable on a daily scale for the observed distances (Table 1).

Figure 4 shows two scatter plots of ULS-derived daily mean sea ice draft versus ADCPderived daily mean sea ice draft at the 1893 and Taymyr stations and from the sampling periods 2013-2014 (13/14) and 2014-2015 (14/15). Pearson correlation coefficients between ULS- and ADCP-derived daily mean ice draft are between 0.71 (Taymyr-14/15) and 0.90 (1893-13/14). Following the $t$-test, all four correlation coefficients were significant at the $99 \%$ confidence level. For the $14 / 15$ period, correlation coefficients were lower than for the 13/14 period, which coincides with the larger distances between ULS and ADCP moorings in 14/15 (Table 1). Figure 5 shows the agreement of the ULS- and ADCP-derived time series 
with time. ADCP-derived time series reproduced the ULS-observed seasonal variability in sea ice draft. Dominant peaks in daily mean ULS ice draft that developed over longer time periods were also observed by the ADCP (example Taymyr-13/14). Noticeable offsets are visible for the Taymyr-13/14 comparison (also visible in Figure 4), where a consistent underestimation by the ADCP is apparent. In contrast with the 1893-14/15 case, this underestimation is independent of season and thickness. The underestimation of ULS results by the ADCP-derived time series in the 1893-14/15 case is most significant during the period when the thickest drafts were observed. Another significant disagreement between the compared time series is that the ADCP time series indicate short infrequent ice-covered periods, even after the ULS time series showed no ice cover in June/July any more.
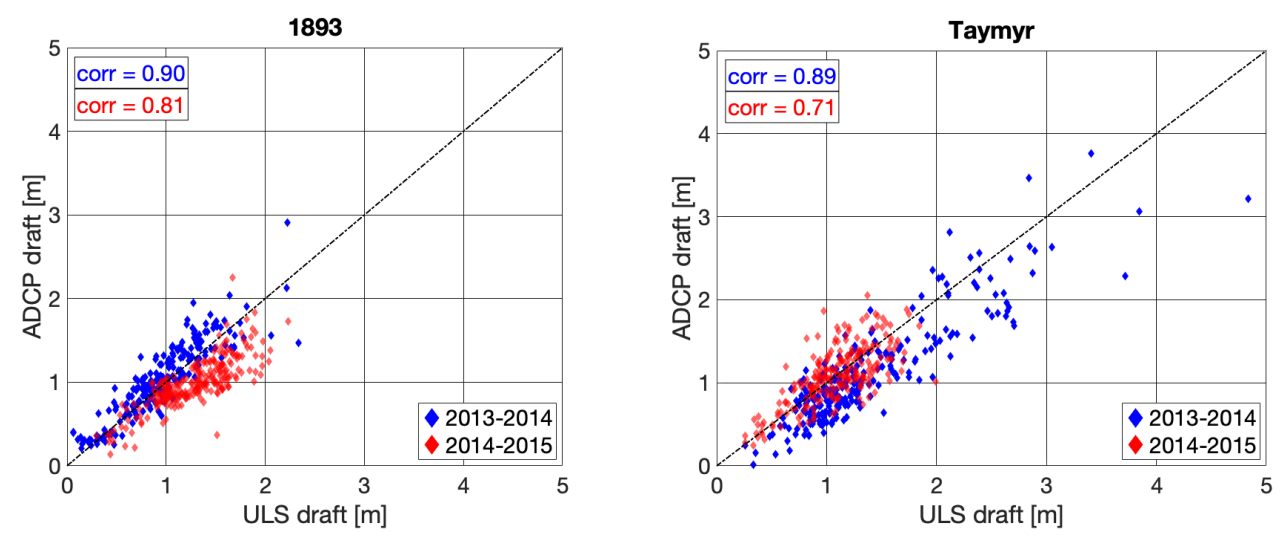

Figure 4. ULS- and ADCP-derived daily mean sea ice draft comparison from the 1893 (left) and Taymyr (right) stations. Blue (red) markers indicate data from the 2013-2014 (2014-2015) sampling period. Values (corr) show Pearson correlation coefficients between ULS- and ADCP-derived sea ice draft for the respective station and sampling period. Correlation coefficients are significant at the $99 \%$ confidence level for all four ULS/ADCP data pairs.
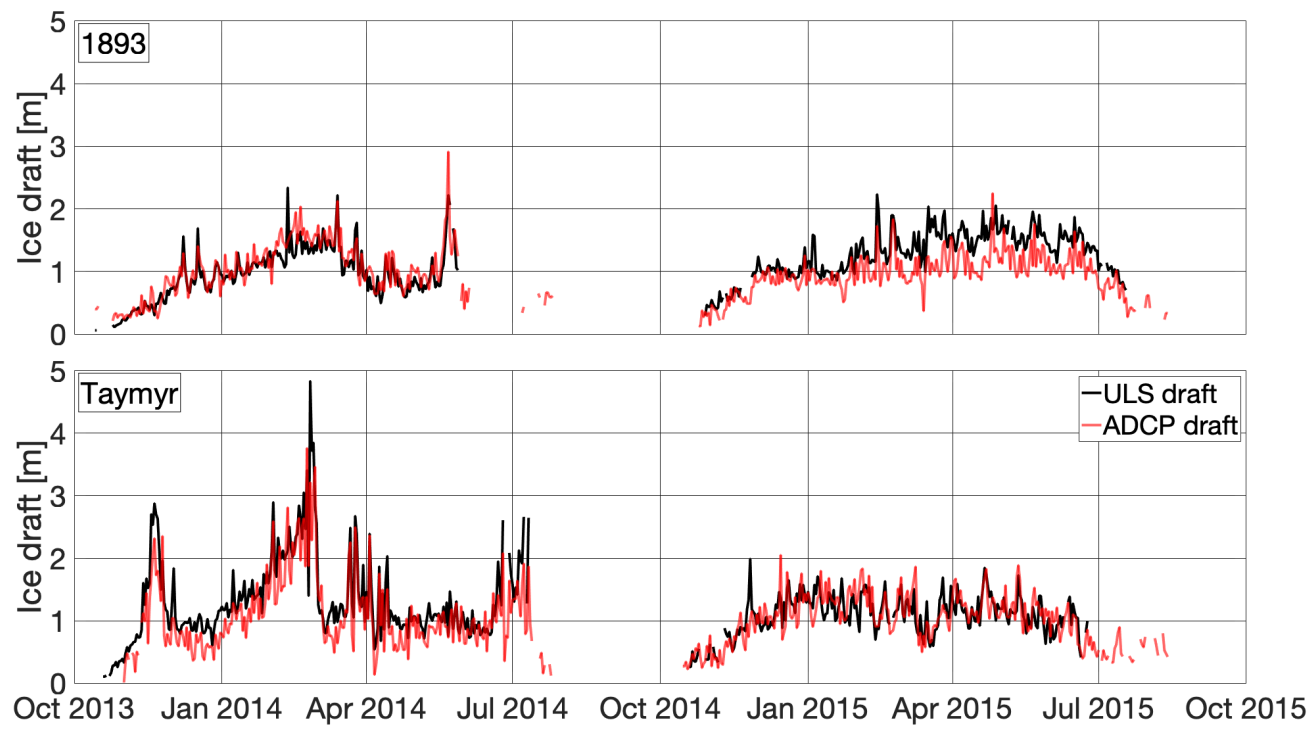

Figure 5. Daily mean sea ice draft time series derived from moored ULSs (black) and ADCPs (red) from the 1893 (top panel) and Taymyr (bottom panel) stations.

In the following, we focus on a number of statistical values to compare ADCP- and ULS-derived daily mean ice draft: mean, median, modal values, percentage deviation as well as the range and offset between the first and third quartiles. We also used these values to determine whether general offsets occur between ULS and ADCP results, that could be 
used to define a general correction factor for ADCP-derived daily mean ice draft. Negative deviations indicate an overestimation of ADCP-derived ice draft compared to the ULS data, while positive deviations represent an underestimation.

The percentage deviations of ADCP-derived daily mean sea ice drafts from the ULSderived daily mean sea ice drafts are shown in Figure 6. Other than the correlation coefficients, mean differences and percentage deviations between ULS- and ADCP-derived ice draft indicate potential offsets between the compared time series in general. The daily percentage deviation values are variable and show large outliers but are consistent over time for three of the four datasets. The 1893-14/15 deviations between ULS- and ADCP-derived draft seem to show a small increasing trend over the sampling period. On average, ADCP-derived draft exceeds the ULS draft by 16.57 and $2.99 \%$ for the 1893 $13 / 14$ and Taymyr-14/15, respectively. For the 1893-14/15 and Taymyr-13/14 data, the ADCP underestimates ULS draft by 21.36 and $18.90 \%$. Daily percentage deviation values indicate a general overestimation (underestimation) by the ADCP for 1893-13/14 (189314/15 and Taymyr-13/14), while Taymyr-14/15 shows no overall tendency for over- or underestimation.
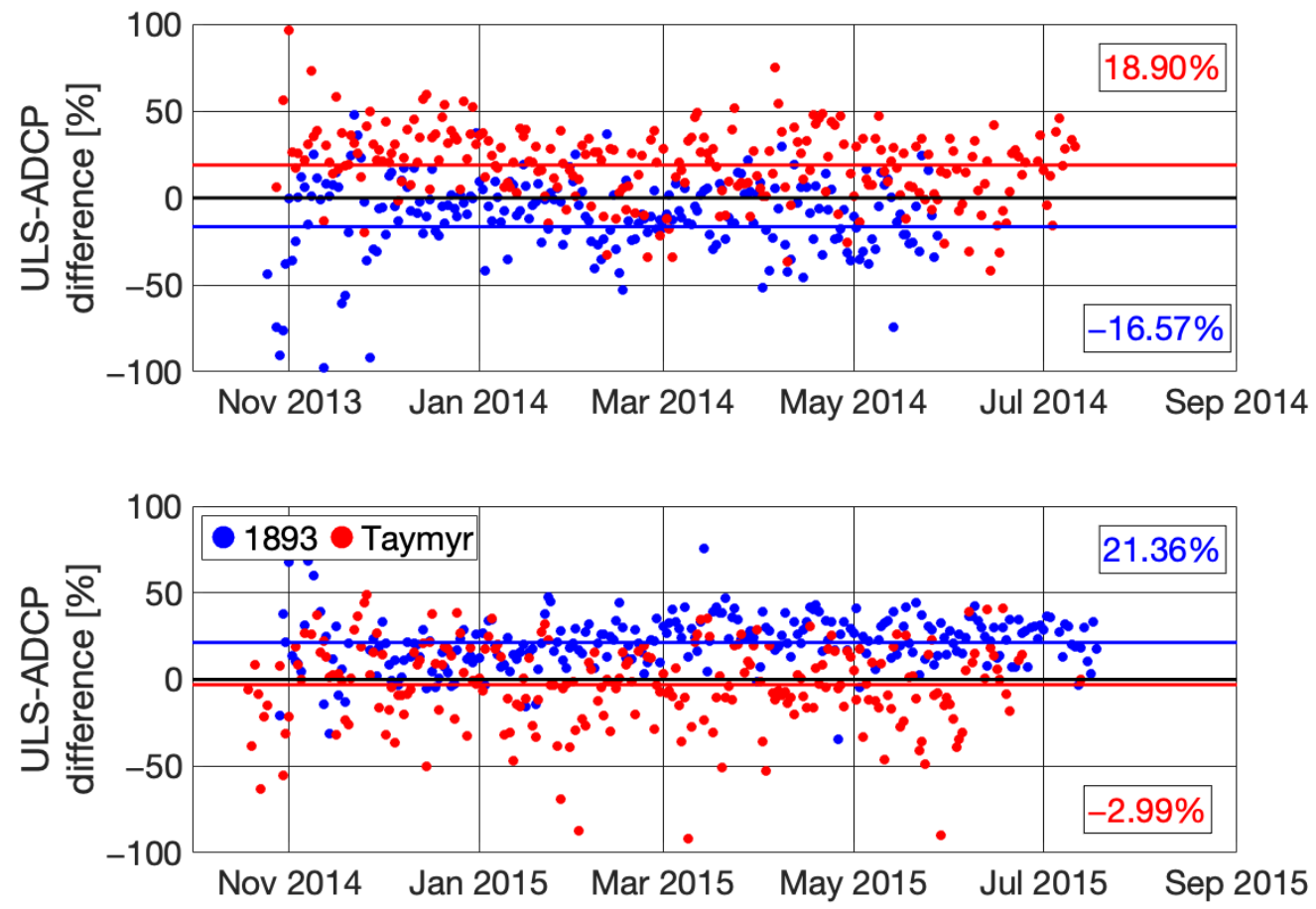

Figure 6. Percentage deviation of ADCP-derived daily mean sea ice draft from ULS-derived daily mean sea ice draft at 1893 (blue) and Taymyr (red) stations. Upper (lower) panel shows the 2013-2014 (2014-2015) sampling period. Solid lines indicate the mean percentage deviation of the ADCP-derived to the ULS-derived daily mean sea ice draft. The respective mean values of the percentage deviation are given on the right (1893 in blue, Taymyr in red).

The largest mean differences are $0.29 \mathrm{~m}$ at station 1893 in $14 / 15$ and $0.25 \mathrm{~m}$ at Taymyr station in 13/14 (Figure 7). Negative mean differences larger than $-0.10 \mathrm{~m}$ occur for the 1893-13/14 and Taymyr-14/15 time series pairs. Largest single datapoint differences occur during spring seasons of both sampling periods (February-March), which also coincide with the largest daily mean ice draft values throughout the individual time series (not shown). 


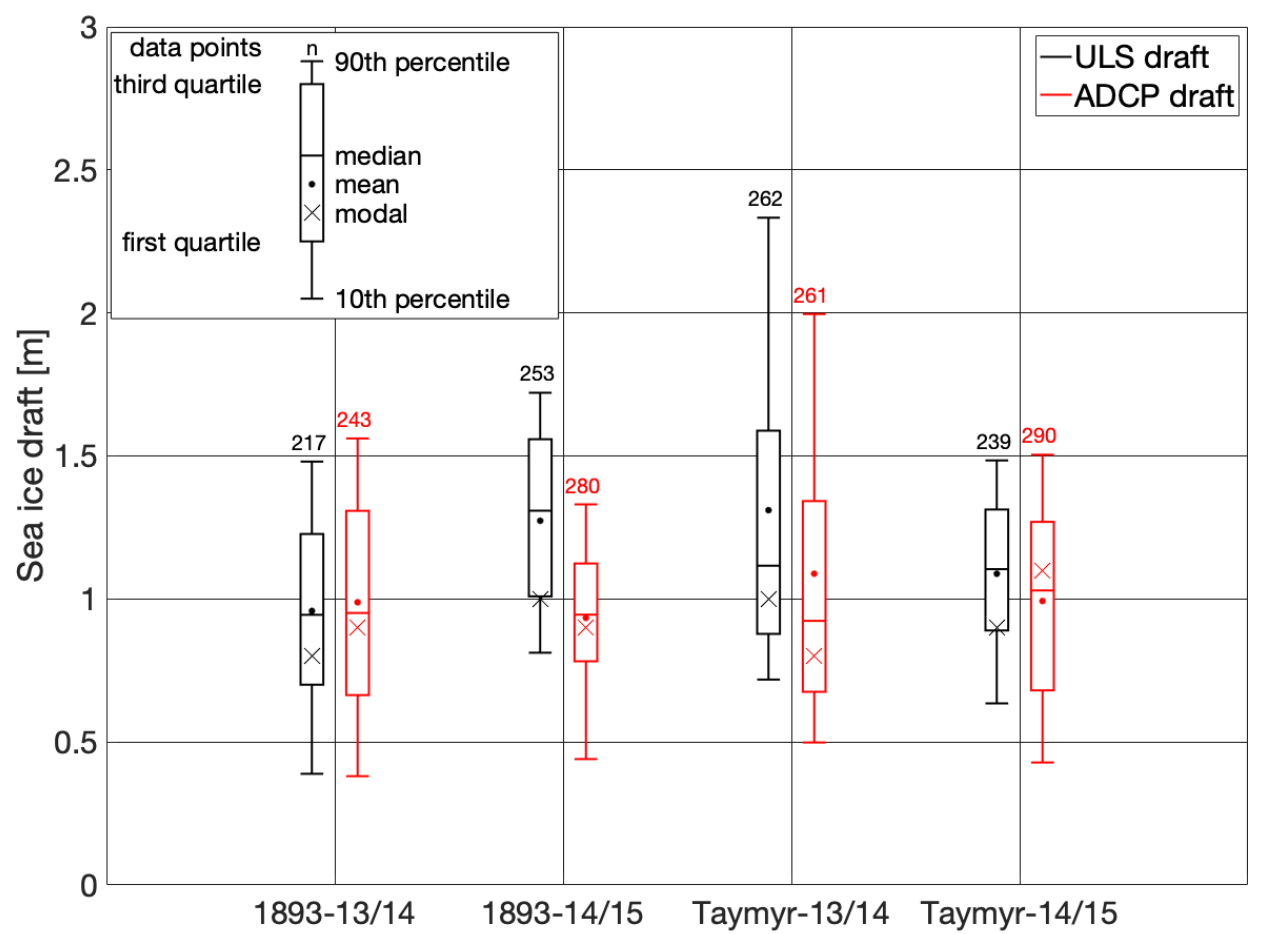

Figure 7. Boxplots for daily mean sea ice draft data, derived from ULS (black) and ADCP (red). Boxes indicate first and third quartiles, while whiskers show the 10th and 90th percentiles of the daily mean ice draft. Filled circles display means over the sampling period, while the horizontal dash gives the median values. The cross-marker provides modal draft values that were evaluated in $0.1 \mathrm{~m}$ bins and the number gives the number of datapoints that went into the statistics. Data are shown for the stations 1893 and Taymyr and for the two sampling periods 2013-2014 (13/14) and 2014-2015 (14/15).

The lowest differences between the mean ULS and ADCP and median ULS and ADCP draft values occur for the 1893-13/14 time series. For the other three dataset pairs, ADCPderived values underestimate ULS means and medians by approximately 0.10 to $0.37 \mathrm{~m}$. Modal values differ between -0.20 and $0.20 \mathrm{~m}$ with no consistent indication for over- or underestimation from the ADCP-derived data.

The spread between the 10th and 90th percentiles is consistent for ULS and ADCP for the four time series pairs. However, except for the 1893-13/14 data, differences between the ULS and ADCP draft values indicate an underestimation of ice draft from ADCP data. This difference is especially pronounced for the 1893-14/15 and Taymyr-13/14 datasets.

After careful evaluation of the above-mentioned statistical values, no consistent offset can be determined. Differences that occur for one or two statistical values at individual stations do not necessarily occur for the others. However, in cases of notable differences between ULS and ADCP time series, more often than not, an underestimation of ADCPderived ice draft compared to ULS-derived values is apparent.

\section{Discussion}

The ADCP's general instrument setup is designed to measure velocity fields within the water column rather than to derive sea ice draft. Therefore, the systematic errors introduced in the ADCP-derived ice draft time series are inherently larger than for ULSbased ice draft measurements. To reduce these errors, previous studies $[10,12]$ developed and applied correction terms for beamwidth bias and sound-speed variations. Both terms aimed to correct the absolute range values that are required for the derivation of ice draft based on pressure-derived instrument depth. In contrast, to utilise the available Laptev Sea ADCP data, we had to overcome the lack of auxiliary pressure data. Hence, contrary to 
the work of Shcherbina et al. [10] and Hyatt et al. [12], our approach is solely based on BT range values to determine instrument depth. This means that our retrieved open-water range values are affected by the above-mentioned biases and errors as well as the range values during ice-covered periods. The largest error is introduced by the rather crude assumption of a constant quasi-depth per beam throughout the entire sampling period. ADCP moorings were deployed at water depths between 45 and $80 \mathrm{~m}$ with approximate instrument depths varying from 34 to $46 \mathrm{~m}$. With mooring lengths between 29 and $59 \mathrm{~m}$ and inevitable mooring motion, the assumption of one constant depth throughout the sampling period is unrealistic. However, for the presented datasets, the agreement between ADCP- and ULS-derived daily mean sea ice draft shows better results for the assumption of a constant instrument depth compared to calculations with time-varying depth.

In the following, we discuss the mentioned correction terms and the extent to which we considered them for the presented approach. In addition, we will discuss the uncertainties that can be expected in the final data product when applying the presented approach of determining instrument depth from open-water BT range values. This is followed by an analysis of the deviations and differences between ULS- and ADCP-derived draft time series that we found in the results.

\subsection{Open-Water Detection}

The presented open-water detection is based on the assumption that all flag values in the error velocity output data result from large inhomogeneities in the velocity field at the surface during open-water conditions. However, it has to be noted that these flag values can also occur from malfunctioning beams and outliers [27]. Even so, our selected open-water datapoints are almost exclusively found during freeze-up, melt, and ice-free periods of the ADCP time series. This is expected, as open-water areas are most frequent during these periods. For short beam malfunctions and outliers, the error velocity data are likely to indicate open-water periods during winter, which is not the case for the presented data. We conclude that beam malfunctions and outliers, if at all, only occurred for a few isolated measurements and not over longer time periods. Furthermore, it is valid to assume that malfunctions of individual beams not only yield flag values in the error velocity output, but also in the range output of the ADCP. Consequently, range values would not have been available for the retrieval of instrument depth, if the open-water datapoint was selected erroneously.

Filtering of outliers and signal spikes that do not represent physical processes is a very important step in signal processing [29]. However, raw ADCP BT data are only filtered for spikes that were caused by physical processes, such as double bounces or returns from bubbles and biota in the water column [25]. Further processing was not conducted because even single outliers of BT range values do not affect our instrument depth determination, since the instrument depth is defined as the most frequent open-water BT range value (Figure 3). Individual datapoints can still be erroneous. However, the careful analysis of the open-water data, the ADCP-internal ensemble averaging, the selection process of the instrument depth, the averaging over the four beams, as well as the final averaging to daily mean values, ensure that the impact of these outliers on the final presented data product is negligible.

For the presented case error, velocities were flagged for values larger than $1 \mathrm{~m} / \mathrm{s}$. This value was pre-set for the given ADCPs and we consider it a definitive indicator of openwater conditions. Large differences in measured vertical velocities between the individual beams are the result of waves at the surface. These can occur in open-water conditions but also during periods dominated by mobile thin ice. At the same time, the selected threshold potentially neglects legitimate open-water areas, e.g., open-water surfaces in light or no wind. Smaller error velocity thresholds were applied as well; however, none of them increased the number of open-water readings during winter in the available ADCP datasets. Therefore, no continuous instrument depth time series could be determined and a constant instrument depth was used for the calculation of ADCP draft. Applying the 
presented instrument depth determination to data from ADCPs that measured with higher frequencies potentially allows for the derivation of an instrument depth time series and, therefore, a more realistic estimate of instrument depth.

Biases in the open-water range can be induced from cloud bubbles submerged by breaking waves or the wrongful detection of open-water in wave-affected thin ice regimes. In addition, ensemble averages of the BT range potentially consist of values obtained from open-water and ice targets, which not only biases the selected open-water, but also range values in periods defined as ice-covered. These biases have to be considered for individual open-water range values and when estimating instrument depth from the mean of all open-water range values, which is why we selected the modal open-water range value for the estimation of constant instrument depth rather than the mean. The crude assumption of constant instrument depth throughout the sampling period is the result of the continuous winter-time ice cover in the Laptev Sea region and the ADCP sampling frequency.

\subsection{Tilt and Beamwidth Bias}

The beamwidth bias arises from the general configuration of the ADCP (Figure 2) and is dependent on instrument tilts, instrument depth, and the roughness of the reflecting surface. Changes in instrument depth and tilts, e.g., through currents, result in a change in beam footprint. Due to the beamwidth of $3.8^{\circ}$ and the default mounting angle ( $20^{\circ}$ to the normal incidence) of the ADCP beams, the location of the echo maximum is shifted to indicate smaller range values [10]. Due to the skewed elliptical footprint and the coincidental shift in the echo intensity maximum, the effective beam angle is smaller than the nominal one. Consequently, BT range values are biased towards being low. Considering a constant instrument depth, this bias is more pronounced during open-water periods than during ice-covered periods, as the reflecting ice surface is closer to the instrument than the open-water surface.

The above-mentioned underestimation of range due to the beamwidth bias is based on the assumption of level surface conditions. Naturally, ice and water surfaces are rough, which introduces additional errors [10]. As a consequence of the comparably large instrument tilts, these errors vary with ice deformation and increasing ice thickness as the insonified area changes [25]. Due to the limited knowledge on the roughness of the reflecting surface, it is almost impossible to define an accurate beamwidth bias correction term without external data.

In summary, for the first-year ice-dominated Laptev Sea, we assume level ice conditions and rely on internal range corrections for the default tilt angle of $20^{\circ}$ to the normal incidence done by the ADCP. Furthermore, we correct the raw BT range data output for tilts measured by the ADCP (roll and pitch). This leads to an underestimation of all BT range values from the ADCP due to the difference between the nominal and effective beam angle. The complex effects of changing beamwidth biases due to uneven ice surfaces are not considered, due to the lack of data available to quantify those variations. Accordingly, the limitations and uncertainties arising from large tilts and footprint variations have to be accepted when applying the presented approach to derive ice draft time series from upward-looking ADCP BT data. However, since both, range and instrument depth are based on the biased BT range values, the influences on the final draft values cancel each other out to some degree. Nevertheless, would it be beneficial to analyse additional $\mathrm{ADCP} / \mathrm{ULS}$ data pairs to investigate how the agreement between ULS and ADCP-derived ice draft is affected by setups with larger tilts or deeper deployments of the ADCP. For the current setup on the shallow shelves in the Laptev Sea, the effects of the beamwidth bias are neglected.

\subsection{Sound-Speed Correction}

Another important correction is required due to the variations in water composition and the resulting change in the two-way travel time of the emitted acoustic signal. There are multiple ways to correct for variations in sound-speed. 
The first correction approach is based on external measurements of water properties. Changes in temperature and salinity have an effect on how fast the acoustic signal travels through the water column. However, temperature and salinity-and, therefore, soundspeed - not only vary in time but also within the vertical profile of the water column [10,12]. This means that, in order to provide an accurate sound-speed correction, external measurements of temperature and salinity are required throughout the entire sampling period but also along the vertical profiles above the ADCPs. Due to the lack of additional measurements along the vertical profile, the applied sound-speed correction only takes temporal changes in sound-speed into account.

Another way of correcting for changes in sound-speed is based on the knowledge of open-water periods, or 'zero drafts' [10,25]. Assuming a draft of zero (open-water) in the uncorrected ice draft time series allows for the computation of a correction factor (using Equation (1)) from the instrument depth, range, and tilt. The correction factor, $\beta$, is considered to be the ratio of empirical to nominal sound-speed. This approach is used to derive sea ice draft from the ULS [25]. However, it requires accurate knowledge of instrument depth during times of open-water, which is not available from the presented Laptev Sea ADCP data. As mentioned before, open-water periods derived from error velocity flag values almost exclusively occur during freeze-up, melt, and ice-free periods in the datasets, i.e., there is almost no open-water data during winter. Additionally, the comparably long sampling interval of $1 \mathrm{~h}$ is not favourable to resolving open-water, especially as the hourly values consist of 60-value ensemble means. Therefore, the 'zero draft' approach is not applicable during the predominantly ice-covered winter months.

The presented approaches to correct for sound-speed variations are based on accurate measurements of either temperature and salinity or pressure. For the Laptev Sea ADCPs, we rely on available temperature and salinity data. BT range values are calculated using the speed of sound estimates based on the ADCPs internal year-long temperature measurements and a pre-set constant salinity value that was measured at mooring deployment. This approach is valid since sound-speed variations are more sensitive to changes in temperature than changes in salinity [12]. However, it has to be noted that the impact of salinity changes over time is not negligible. This is especially true in the Laptev Sea, which is characterized by seasonal but also interannual variability in ocean stratification as a result of changes in water composition from river discharge and changes in wind forcing and sea ice cover [30,31]. In the central Laptev Sea, the well-mixed summer surface layer (upper $50 \mathrm{~m}$ ) shows salinities of approximately 34 PSU [31]. In the presence of ice cover, salinities close to the water surface (upper 10-20 m) can decrease to values of around 22 PSU [31,32]. Seasonal variations in salinity of that magnitude change the travel speed of an acoustic signal in the water column and translate to range variations of approximately $0.1 \mathrm{~m}$ in the Laptev Sea (assuming a simple two-layer water column).

As a consequence of the assumption of one constant quasi-depth per beam for the full sampling period, the long sampling intervals, and the lack of auxiliary data, a more comprehensive sound-speed correction, although preferable, is not possible in our case. We, therefore, rely on the ADCPs internal sound-speed correction using year-long temperature measurements and a constant salinity value.

\subsection{Uncertainty Estimates}

Estimating the uncertainty of sea ice draft from upward-looking ADCPs is challenging and requires a number of assumptions about the influencing parameters. Uncertainties of the derived sea ice draft values arise from the ADCP range and tilt measurements, as well as the determination of instrument depth, beamwidth bias, and sound-speed variations. Corrections for these parameters depend on information on the roughness of the reflecting surface, vertical and temporal changes in water composition, and accurate pressure measurements from the ADCP. Most of these additional details were not available for this study because they were not routinely measured from the moorings. To provide a 
rough uncertainty estimate, we consider all available data to determine the uncertainties of the parameters involved in Equation (3).

There are two sources of uncertainty: random uncertainties that arise from measurement fluctuations and systematic uncertainties that have a specific cause and occur for all measurements equally. Biases and systematic uncertainties are very much dependent on the specific instruments and need to be considered for each dataset separately. For the presented estimation of sea ice draft uncertainty we focus on the random uncertainties of the individual parameters of Equation (3).

In order to determine the individual uncertainties that combine for the total uncertainty of the hourly mean sea ice draft from upward-looking ADCPs, $\sigma_{d}$, we divide Equation (3) into two parts and estimate uncertainty for each one of them separately. Following the Joint Committee for Guides in Metrology [33] the combined total uncertainty is given by:

$$
\sigma_{d}=\frac{\sqrt{\sum_{i=1}^{n} \sigma_{z_{i}}^{2}+\sigma_{r_{i_{\phi}}}^{2}}}{\sqrt{n}},
$$

with $\sigma_{z_{i}}$ being the uncertainty of the instrument depth and $\sigma_{r_{i}}$ the uncertainty of the tilt-corrected range for each of the $n$ beams.

\subsubsection{Range Uncertainty}

Since the tilt-corrected raw ADCP range output is the basis for determining instrument depth we first estimate the uncertainty of the hourly ADCP range values. Following [27], the range measurement uncertainty, $\sigma_{r_{i}}$, is about $\pm 1 \%$ of the total measured range, which means that it varies throughout our sampling periods. For the depths of the four presented $\mathrm{ADCPs}$, uncertainties range from approximately \pm 0.3 to $\pm 0.5 \mathrm{~m}$. The ADCP hourly range data output is an ensemble mean of 60 values that were measured at a 1 min sampling interval. Although range values certainly differ on the scale of minutes the ADCP output data only provide one ensemble mean value. To estimate the uncertainty of the hourly range values, we assume that the range variations within one hour are small enough that each measurement can be considered one of a 60 sample measurement of an hourly range value. This assumption neglects any type of range variation on the sub-hourly scale, but is necessary since the initially measured 60 hourly values are not available. Following this assumption, the uncertainty of the ensemble mean range value decreases with $\sqrt{60}$. For longer sampling and averaging intervals, this assumption needs to be reconsidered, since the variability in the individual values adds to the uncertainty of a mean value.

The ADCP corrects for the default $20^{\circ}$ mounting angle to the vertical and for soundspeed variations, which means that the estimated range uncertainty, $\sigma_{r_{i}}$ already includes the uncertainties that arise from these corrections. Therefore, we consider $\sigma_{r_{i}}$ to be the uncertainty of the raw hourly $\mathrm{ADCP}$ range values that were retrieved from the instrument after mooring recovery.

Before calculating the instrument depth and sea ice draft, raw ADCP range data were corrected for additional instrument tilt. The uncertainty of the ADCPs tilt sensors, $\sigma_{\phi}$, is approximately $\pm 1^{\circ}$ [34]. The uncertainty is individually calculated into the range equivalent for each measurement and beam. Like the range uncertainty it is specific to each datapoint and variable throughout the sampling period. Combining $\sigma_{r_{i}}$ and $\sigma_{\phi}$ as the root sum of their squares [33] provides the uncertainty of the tilt-corrected hourly range values, $\sigma_{r_{i}}$.

\subsubsection{Instrument Depth Uncertainty}

The parameter introducing the biggest fraction to the combined uncertainty of hourly sea ice draft values is the instrument depth. Instrument depth is determined to be the most frequently occurring open-water range value (modal open-water range) and is calculated for each ADCP beam individually. We assume the distribution of open-water range values from the $\mathrm{ADCP}$ to be approximately normal. This is valid since the high-temporal- 
resolution range measurements from the ULS show that open-water range values are, in fact, distributed normally. Deviations from the normal distribution visible in the ADCP open-water range data (Figure 3) are likely a result of the averaging to hourly range values and the inherent low temporal resolution of the ADCP data. The assumption of normal distribution of open-water range values allows us to roughly estimate the uncertainty of the modal open-water range from the standard deviation of all open-water range values. Since instrument depth is determined based on ADCP open-water range values, its combined uncertainty is the root sum of the squared tilt corrected range uncertainty, $\sigma_{r_{i_{\phi}}}$, and the uncertainty of selecting the modal open-water range, $\sigma_{z_{i}}$, squared.

Following the averaging over the four ADCP beams (Equation (4)) the mean combined uncertainty for the four presented hourly ADCP sea ice draft time series is approximately $\pm 0.96 \mathrm{~m}$. The instrument depth uncertainty dominates this value and leads to almost constant uncertainty throughout the entire sampling period. Due to the limited amount of data available, this can only be considered a rough uncertainty estimate. Furthermore, it has to be noted that this average uncertainty value is only valid for the presented ADCP hourly sea ice draft time series. Uncertainties of the four presented sea ice draft time series are very similar, but need to be estimated for each new dataset individually. The uncertainties of the daily mean values are even larger, as the daily mean values are also dependent on the variance in the hourly values.

\subsection{ULS- versus ADCP-Derived Ice Draft}

Deviations between ULS- and ADCP-derived daily mean drafts are expected, due to the different processing methods for range data from the compared systems and the different sampling frequencies of the two instruments. Furthermore, upward-looking ADCPs and ULSs were never deployed at the same location, which certainly leads to deviations in the final results as different pieces of sea ice were sampled. In addition, uncertainties in instrument depth and changes in water composition and, therefore, soundspeed variations affect the deviation of the ADCP from the ULS results and whether the ADCP draft over- or underestimates the ULS draft. Despite these influencing factors, corresponding ULS- and ADCP-derived ice draft time series show strong correlations (Figure 4). Regardless of these correlations, offsets between ULS- and ADCP-derived time series are apparent for individual data pairs (Figures 6 and 7). These offsets are not consistent for the four presented data pairs and therefore cannot be attributed to general deficiencies in the presented method of deriving sea ice draft from upward-looking ADCPs. In fact, underestimations of ADCP results from stations Taymyr-13/14 and 1893-14/15 potentially result from a sensor-specific bias. Data from these two stations originate from the same ADCP sensor (RDI ADCP $300 \mathrm{kHz}$, serial number: 12667) and the mean percentage deviations (18.90 and $21.36 \%$ ) and mean underestimations $(0.25$ and $0.29 \mathrm{~m})$ of the two datasets are of a similar magnitude. After the recovery in autumn 2014, the Taymyr mooring was redeployed at the 1893 mooring site for the 14/15 sampling period. The assumption that the offset is systematic, induced by the specific sensor, is confirmed by the fact that the correlation coefficients from the respective data pairs are not affected. Correlation coefficients between ULS- and ADCP-derived ice draft time series are 0.89 and 0.80 , respectively. While the 1893-13/14 ULS followed the same deployment-redeployment pattern, the ADCP sensor was substituted and a new sensor was deployed at the Taymyr station for the 14/15 sampling period. The corresponding mean differences between the two ULS- and ADCP-derived time series indicate a comparably small overestimation by these ADCPs. On average, the unbiased ADCP-derived daily mean drafts overestimate the ULS drafts by approximately $0.1 \mathrm{~m}$.

The variations in correlation coefficients likely result from the inherent superiority of the ULS over the ADCP data, but, more importantly, the fact that ULS and ADCP measured at different locations. In fact, the highest correlation coefficients between ULS- and ADCPderived time series occurred for the cases where ULS and ADCP moorings were deployed closest to each other. The agreement of the daily mean draft time series is very dependent 
on whether the same ice is sampled by ULS and ADCP. With the increasing distance between ADCP and ULS mooring, the likelihood of measuring the same ice decreases due to the strong dependency on the direction and speed of the ice drift. Therefore, it might be valid to assume that a comparison of ice draft values from ADCP and ULS that are approximately 0.99 or $2.85 \mathrm{~km}$ apart from each other is not justified. However, it is impossible to compare the same pieces of sea ice for the given two-mooring setup. The fact that daily means are compared accounts for some of the influence by sea ice drift in regions that are very similar in ice type. Therefore, the displacement between ULS and ADCP moorings is considered small enough for a comparison of their sea ice draft time series.

Finally, the disagreement in ice occurrence in June/July between ADCP and ULS draft time series is considered to be a result of the sampling frequency and the ensemble averaging of the ADCP. While individual ice floes that are present in June/July in the Laptev Sea contribute to a larger degree to the ADCP's daily mean sea ice draft time series, they only represent an insignificant fraction of the 86400 datapoints recorded by the ULS each day.

\section{Conclusions}

Daily mean ice draft time series can be derived using upward-looking ADCPs, even if auxiliary pressure sensor data are not available. Previous efforts to derive ice draft from ADCPs relied on accurate pressure recordings to calculate ADCP instrument depth. However, we show that instrument depth can also be inferred from BT range values during open-water periods. The distinction between ice-covered and open-water periods is based on error velocity output data from the upward-looking ADCP.

Although this method is not sufficient to derive high-frequency ice draft time series, like ULS systems, it provides a low-cost opportunity to compute daily mean ice draft time series from upward-looking ADCP BT data that are, on average, within approximately $20 \%$ of the ULS-derived drafts. More importantly, it allows for revisiting existing ADCP records that have not been utilised to derive ice draft time series, due to lacking auxiliary pressure data. For the four presented ADCP datasets, the uncertainty of the hourly sea ice draft values is approximately $\pm 0.96 \mathrm{~m}$ on average. However, every ADCP dataset and the corresponding uncertainties should be carefully evaluated, since higher sampling frequencies or ice regimes different from the one in the Laptev Sea allow for more sophisticated detections of instrument depth.

The ADCP data utilised in this study were recorded to provide complementary ice drift data to ULS draft time series. This fortunate setup, with the two moorings being deployed next to each other, enabled us to reference the ADCP-derived ice drafts to ULSderived data that are considered the primary source of high-frequency, high-precision ice draft time series. The comparison with ULS data was one key factor that was missing in previous derivations of ice draft time series from upward-looking ADCPs and validates our presented approach. However, we have to point out that more comparisons are required to further validate the presented results.

The presented method is explicitly not a substitute for the ice draft time series derived from ULSs and will never reach the same level of accuracy or temporal resolution. Furthermore, the presented daily mean sea ice draft time series show significant uncertainties, which users should consider when using the data. Future ice draft measurements should still be conducted using ULSs or, if necessary, upward-looking ADCPs with higher sampling frequencies and additional pressure sensors. Furthermore, pre-ULS data from upward-looking ADCPs with reliable pressure information should be processed following the methods published by Shcherbina et al. [10] and Hyatt et al. [12]. However, the presented method adapts to the data and instrument limitations in regions where ULS records are limited or simply not available, and enables the extension of ice draft time series into the past with data that have been unsuitable for that purpose to date. Based on the ADCP data made available because of this study, the sea ice draft data archive of the Laptev Sea can be significantly extended. These data are vital, since the Laptev Sea is among the most 
difficult to access, and hence among the most understudied marginal seas in the Arctic. Furthermore, we gain access to unique validation data for weekly and monthly mean sea ice thickness products from satellite missions such as CryoSat-2, SMOS or ENVISAT.

Author Contributions: Conceptualization: H.J.B., T.K., M.A.J.; methodology: H.J.B. and M.A.J.; formal analysis: H.J.B.; writing—original draft preparation: H.J.B.; writing—review and editing: H.J.B., T.K., M.A.J., C.H.; investigation: M.A.J; resources: E.R.; software: E.R.; data curation: E.R. and H.J.B.; supervision: T.K. and C.H.; funding acquisition: C.H. and T.K. All authors have read and agreed to the published version of the manuscript.

Funding: This study was carried out as part of the BMBF-funded Russian-German research cooperation QUARCCS (grant: 03F0777A). Moorings were deployed and recovered within the framework of the Russian-German project CATS/Transdrift (grant: 63A0028B).

Data Availability Statement: ULS and raw ADCP bottom track data are accessible at the Data Publisher for Earth \& Environmental Science PANGAEA [35,36].

Acknowledgments: The 2013/2014 ULS datasets were processed by ASL Environmental Sciences Inc., Victoria, BC, Canada. ASL also provided valuable support and the toolboxes for the processing of the 2014/2015 ULS datasets. Additionally, the ECMWF provided ERA-Interim reanalysis surface pressure data [26] that were valuable for the ULS processing. Special thanks to all the people involved on the various expeditions. We acknowledge support by the Open Access Publication Funds of Alfred Wegener Institute, Helmholtz Centre for Polar and Marine Research. Finally, we would like to thank the handling editor Bobby Wang, the team at MDPI, and the two anonymous reviewers for their valuable input and support.

Conflicts of Interest: The authors declare no conflict of interest.

\section{References}

1. Ross, E.; Clarke, M.; Fissel, D.B.; Chave, R.A.J.; Johnston, P.; Buermans, J.; Lemon, D. Testing of Ice Profiler Sonar (IPS) Targets Using a Logarithmic Detector; ASL Environmental Science Inc.: Saanichton, BC, Canada: 2016.

2. Melling, H.; Riedel, D.A. The underside topography of sea ice over the continental shelf of the Beaufort Sea in the winter of 1990. J. Geophys. Res. 1995, 100, 13641-13653. doi: 10.1029/95JC00309. [CrossRef]

3. Vinje, T.; Nordlund, N.; Kvambekk, A. Monitoring ice thickness in Fram Strait. J. Geophys. Res. Ocean. 1998, 103, 10437-10449. doi: 10.1029/97JC03360. [CrossRef]

4. Fukamachi, Y.; Mizuta, G.; Ohshima, K.I.; Melling, H.; Fissel, D.; Wakatsuchi, M. Variability of sea-ice draft off Hokkaido in the Sea of Okhotsk revealed by a moored ice-profiling sonar in winter of 1999. Geophys. Res. Lett. 2003, 30. doi: 10.1029/2002GL016197. [CrossRef]

5. Hansen, E.; Gerland, S.; Granskog, M.A.; Pavlova, O.; Renner, A.H.H.; Haapala, J.; Loyning, T.B.; Tschudi, M. Thinning of Arctic sea ice observed on Fram Strait: 1990-2011. J. Geophys. Res. Ocean. 2013, 118, 5202-5221. doi: 10.1002/jgrc.20393. [CrossRef]

6. Krishfield, R.A.; Proshutinsky, A.; Tateyama, K.; Williams, W.J.; Carmack, E.C.; McLaughlin, F.A.; Timmermans, M.L. Deterioration of perennial sea ice in the Beaufort Gyre from 2003 to 2012 and its impact on the oceanic freshwater cycle. J. Geophys. Res. Ocean. 2014, 119, 1271-1305. doi: 10.1002/2013JC008999. [CrossRef]

7. Behrendt, A.; Dierking, W.; Witte, H. Thermodynamic sea ice growth in the central Wedell Sea, observed in upward-looking sonar data. J. Geophys. Res. Ocean. 2015, 120, 2270-2286. doi: 10.1002/2014JC010408. [CrossRef]

8. Janout, M.A.; Hoelemann, J.; Waite, A.M.; Krumpen, T.; von Appen, W.J.; Martynov, F. Sea-ice retreat controls timing of summer plankton blooms in the Eastern Arctic Ocean. Geophys. Res. Lett. 2016, 43. doi: 10.1002/2016GL071232. [CrossRef]

9. Fukamachi, Y.; Simizu, D.; Ohshima, K.I.; Eicken, H.; Mahoney, A.R.; Iwamoto, K.; Moriya, E.; Nihashi, S. Sea-ice thickness in the coastal northeastern Chukchi Sea from moored ice-profiling sonar. J. Glaciol. 2017, 63, 888-898. doi: 10.1017/jog.2017.56. [CrossRef]

10. Shcherbina, A.Y.; Rudnick, D.L.; Talley, L.D. Ice-Draft Profiling from Bottom-Mounted ADCP Data. J. Atmos. Ocean. Technol. 2005, 22, 1249-1266. doi: 10.1175/JTECH1776.1. [CrossRef]

11. Banks, C.J.; Brandon, M.A.; Garthwaite, P.H. Measurement of sea-ice draft using upward-looking ADCP on an autonomous under water vehicle. Ann. Glaciol. 2006, 44, 211-216. doi: 10.3189/172756406781811871. [CrossRef]

12. Hyatt, J.; Visbeck, M.; Beardsley, R.C.; BrechnerOwens, W. Estimating sea-ice coverage, draft, and velocity in Marguerite Bay (Antarctica) using a subsurface moored upward-looking acoustic Doppler current profiler (ADCP). Deep.-Sea Res. II 2008, 55, 351-364. doi: 10.1016/j.dsr2.2007.11.004. [CrossRef]

13. Bjoerk, G.; Nohr, C.; Gustafsson, B.G.; Lindberg, A.E.B. Ice dynamics in the Bothnian Bay inferred from ADCP measurements. Tellus 2008, 60, 178-188. doi: 10.1111/j.1600-0870.2007.00282.x. [CrossRef] 
14. Belliveau, D.; Budgen, G.L.; Eid, B.M.; Calnan, C.J. Sea Ice Velocity Measurements by Upward-Looking Doppler Current Profilers. J. Atmos. Ocean. Technol. 1990, 7, 596-602. doi: 10.1175/1520-0426(1990)007<0596:SIVMBU>2.0.CO;2. [CrossRef]

15. Melling, H.; Johnston, P.H.; Riedel, D.A. Measurements of the Underside Topography of Sea Ice by Moored Subsea Sonar. J. Atmos. Ocean. Technol. 1995, 12, 589-602. doi: 10.1175/1520-0426(1995)012<0589:MOTUTO>2.0.CO;2. [CrossRef]

16. Visbeck, M.; Fischer, J. Sea Surface Conditions Remotely Sensed by Upward-looking ADCPs. Am. Meteorol. Soc. 1995, 12, 141-149. doi: 10.1175/1520-0426(1995)012<0141:SSCRSB>2.0.CO;2. [CrossRef]

17. Schaffer, J.; Timmermann, R.; Arndt, J.E.; Kristensen, S.S.; Mayer, C.; Morlighem, M.; Steinhage, D. A global, high-resolution data set of ice sheet topography, cavity geometry, and ocean bathymetry. Earth Syst. Sci. Data 2016, 8, 543-557. doi: 10.5194/essd-8543-2016. [CrossRef]

18. Rigor, I.G.; Wallace, J.M.; Colony, R.L. Response of Sea Ice to the Arctic Oscillation. J. Clim. 2002, 15, 2648-2663. doi: 10.1175/1520-0442(2002)015<2648:ROSITT>2.0.CO;2. [CrossRef]

19. Krumpen, T.; Janout, M.; Hodges, K.I.; Gerdes, R.; Girard-Ardhuin, F.; Hoelemann, J.; Willmes, S. Variability and trends in Laptev Sea ice outflow between 1992-2011. Cryosphere 2013, 7, 349-363. doi: 10.5194/tc-7-349-2013. [CrossRef]

20. Krumpen, T.; Belter, H.J.; Boetius, A.; Damm, E.; Haas, C.; Hendricks, S.; Nicolaus, M.; Noethig, E.M.; Paul, S.; Peeken, I.; et al. Arctic Warming interrupts the Transpolar Drift and affects long-range transport of sea ice and ice-rafted matter. Nat. Sci. Rep. 2019, 9, 5459. doi: 10.1038/s41598-019-41456-y. [CrossRef] [PubMed]

21. Reimnitz, E.; Dethleff, D.; Nuernberg, D. Contrasts in Arctic shelf sea-ice regimes and some implications: Beaufort Sea versus Laptev Sea. Mar. Geol. 1994, 119, 215-225. doi: 10.1016/0025-3227(94)90182-1. [CrossRef]

22. Bareiss, J.; Goergen, K. Spatial and temporal variability of sea ice in the Laptev Sea: Analyses and review of satellite passivemicrowave data and model results, 1979 to 2002. Glob. Planet. Chang. 2005, 48, 28-54. doi: 10.1016/j.gloplacha.2004.12.004. [CrossRef]

23. Timokhov, L.A. Regional characteristics of the Laptev and the East Siberian seas: climate, topography, ice phases, thermohaline regime, circulation. Berichte Polarforsch. 1994, 114, 15-32.

24. Janout, M.A.; Lenn, Y.D. Semidiurnal Tides on the Laptev Sea Shelf with Implications for Shear and Vertical Mixing. J. Phys. Oceanogr. 2014, 44, 202-219. doi: 10.1175/JPO-D-12-0240.1. [CrossRef]

25. ASL. IPS Processing Toolbox User's Guide; ASL Environmental Sciences Inc.: Victoria, BC, Canada, 2017.

26. Dee, D.P.; Uppala, S.M.; Simmons, A.J.; Berrisford, P.; Poli, P.; Kobayashi, S.; Andrae, U.; Balmaseda, M.A.; Balsamo, G.; Bauer, P.; et al. The ERA-Interim reanalysis: configuration and performance of the data assimilation system. Q. J. R. Meteorol. Soc. 2011, 137, 553-597. doi: 10.1002/qj.828. [CrossRef]

27. Teledyne RD Instruments. Acoustic Doppler Current Profiler—Principles of Operation—A Practical Primer; Technical Report; Teledyne RD Instruments: Poway, CA, USA, 2011.

28. Teledyne RD Instruments. ADCP_Coordinate Transformation-Formulas and Calculations; Technical Report; Teledyne RD Instruments: Poway, CA, USA, 2008.

29. Starkenburg, D.; Metzger, S.; Fochesatto, G.J.; Alfieri, J.G.; Gens, R.; Prakash, A.; Cristobal, J. Assessment of Despiking Methods for Turbulence Data in Micrometeorology. J. Atmos. Ocean. Technol. 2016, 33, 2001-2013. doi: 10.1175/JTECH-D-15-0154.1. [CrossRef]

30. Bauch, D.; Hoelemann, J.; Willmes, S.; Gröger, M.; Novikhin, A.; Nikulina, A.; Kassens, H.; Timokhov, L. Changes in distribution of brine waters on the Laptev Sea shelf in 2007. J. Geophys. Res. Ocean. 2010, 115. doi: 10.1029/2010JC006249. [CrossRef]

31. Janout, M.A.; Hoelemann, J.; Laukert, G.; Smirnov, A.; Krumpen, T.; Bauch, D.; Timokhov, L. On the Variability of Stratification in the Freshwater-Influenced Laptev Sea Region. Front. Mar. Sci. 2020, 7, 543489. doi: 10.3389/fmars.2020.543489. [CrossRef]

32. Osadchiev, A.A.; Pisareva, M.N.; Spivak, E.A.; Shchuka, S.A.; Semiletov, I.P. Freshwater transport between the Kara, Laptev, and East-Siberian seas. Sci. Rep. 2020, 10, 13041. doi: 10.1038/s41598-020-70096-w. [CrossRef]

33. JCGM. JCGM 100: Evaluation of Measurement Data-Guide to the Expression of Uncertainty in Measurement (GUM1995); International Organization for Standardization: Geneva, Switzerland, 2008.

34. Teledyne RD Instruments. WorkHorse-Sentinel, Monitor, Mariner Operation Manual; Teledyne RD Instruments: Poway, CA, USA, 2014.

35. Belter, H.J.; Janout, M.A.; Krumpen, T.; Hoelemann, J.A.; Timokhov, L.; Novikhin, A.; Kassens, H. Raw Bottom Track Error Velocity and Range Data from Moored Upward-Looking Acoustic Doppler Current Profilers in the Laptev Sea between 2013 and 2015; PANGAEA: Bremen, Germany, 2019. doi: 10.1594/PANGAEA.899269. [CrossRef]

36. Belter, H.J.; Janout, M.A.; Krumpen, T.; Ross, E.; Hoelemann, J.A.; Timokhov, L.; Novikhin, A.; Kassens, H.; Wyatt, G.; Rousseau, S.; et al. Daily Mean Sea Ice Draft from Moored Upward-Looking Sonars in the Laptev Sea between 2013 and 2015; PANGAEA: Bremen, Germany, 2019. doi: 10.1594/PANGAEA.899275. [CrossRef] 